\title{
Overview of the Physics and Engineering Design of NSTX Upgrade.
}

J. E. Menard et. al

July 5,2011

The 38th IEEE International Conference on Plasma Science (ICOPS) and 24th Symposium on Fusion Engineering (SOFE) Chicago, IL, United States June 26, 2011 through June 30, 2011 
This document was prepared as an account of work sponsored by an agency of the United States government. Neither the United States government nor Lawrence Livermore National Security, LLC, nor any of their employees makes any warranty, expressed or implied, or assumes any legal liability or responsibility for the accuracy, completeness, or usefulness of any information, apparatus, product, or process disclosed, or represents that its use would not infringe privately owned rights. Reference herein to any specific commercial product, process, or service by trade name, trademark, manufacturer, or otherwise does not necessarily constitute or imply its endorsement, recommendation, or favoring by the United States government or Lawrence Livermore National Security, LLC. The views and opinions of authors expressed herein do not necessarily state or reflect those of the United States government or Lawrence Livermore National Security, LLC, and shall not be used for advertising or product endorsement purposes. 


\title{
Overview of the Physics and Engineering Design of NSTX Upgrade
}

\author{
(Invited Paper)
}

\author{
J. Menard*, J. Canik ${ }^{\dagger}$, J. Chrzanowski*, M. Denault*, L. Dudek*, S. Gerhardt*, S. Kaye*, C. Kessel*, \\ E. Kolemen*, R. Maingi ${ }^{\dagger}$, C. Neumeyer*, M. Ono*, E. Perry*, R. Raman ${ }^{\ddagger}$, S. Sabbagh ${ }^{\S}$, M. Smith*, \\ V. Soukhanovskii ${ }^{\Uparrow}$, T. Stevenson*, R. Strykowsky*, P. Titus*, K. Tresemer*, M. Viola*, M. Williams*, \\ and the NSTX Research Team \\ * Princeton Plasma Physics Laboratory, Princeton, NJ, USA \\ †Oak Ridge National Laboratory, Oak Ridge, TN, USA \\ $\ddagger$ University of Washington, Seattle, WA, USA \\ ${ }^{\S}$ Columbia University, New York, NY, USA \\ ^Lawrence Livermore National Laboratory, Livermore, CA, USA
}

\begin{abstract}
The spherical tokamak (ST) is a leading candidate for a fusion nuclear science facility (FNSF) due to its compact size and modular configuration. The National Spherical Torus eXperiment (NSTX) is a MA-class ST facility in the U.S. actively developing the physics basis for an ST-based FNSF. In plasma transport research, ST experiments exhibit a strong (nearly inverse) scaling of normalized confinement with collisionality, and if this trend holds at low collisionality, high fusion neutron fluences could be achievable in very compact ST devices. A major motivation for the NSTX Upgrade (NSTX-U) is to span the next factor of 3-6 reduction in collisionality. To achieve this collisionality reduction with equilibrated profiles, NSTX-U will double the toroidal field, plasma current, and NBI heating power and increase the pulse length from 1-1.5s to $5 \mathrm{~s}$. In the area of stability and advanced scenarios, plasmas with higher aspect ratio and elongation, high $\boldsymbol{\beta}_{N}$, and broad current profiles approaching those of an ST-based FNSF have been produced in NSTX using active control of the plasma $\beta$ and advanced resistive wall mode control. High non-inductive current fractions of $70 \%$ have been sustained for many current diffusion times, and the more tangential injection of the 2nd NBI of the Upgrade is projected to increase the NBI current drive by up to a factor of 2 and support $100 \%$ non-inductive operation. More tangential NBI injection is also projected to provide non-solenoidal current ramp-up (from $I_{P}=0.4 \mathrm{MA}$ up to 0.8-1MA) as needed for an ST-based FNSF. In boundary physics, NSTX and higher-A tokamaks measure an inverse relationship between the scrape-off layer heat-flux width and plasma current that could unfavorably impact nextstep devices. Recently, NSTX has successfully demonstrated very high flux expansion and substantial heat-flux reduction using a snowflake divertor configuration, and this type of divertor is incorporated in the NSTX-U design. The physics and engineering design supporting NSTX Upgrade are described.
\end{abstract}

\section{INTRODUCTION}

The spherical tokamak (ST) is a leading candidate for a fusion nuclear science facility (FNSF) due to its compact size and modular configuration [1], [2]. The National Spherical Torus eXperiment (NSTX) is a MA-class ST facility in the U.S. actively developing the physics basis for an ST-based FNSF. Access to low collisionality $\nu^{*}$ plasmas in the ST configuration is particularly important to more fully understand transport, stability, and non-inductive start-up and

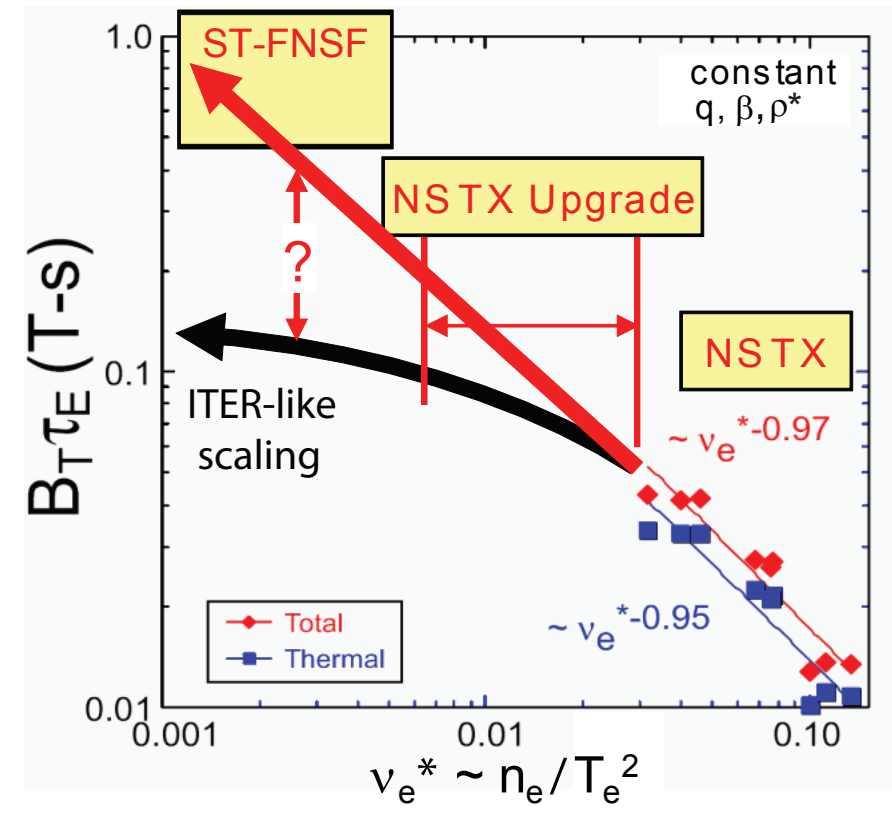

Fig. 1. Product of toroidal field $\left(B_{T}\right)$ and energy confinement time $\left(\tau_{E}\right)$ versus $\nu_{e}^{*}$ for NSTX and projections for NSTX Upgrade and ST-FNSF for ITER H-mode and ST confinement scalings.

sustainment in the spherical torus/tokamak (ST). In particular, NSTX [3] and MAST [4] observe a strong (nearly inverse) scaling of normalized confinement with $\nu^{*}$. An example of this scaling is show in Figure 1 for NSTX experiments in which the plasma $q, \beta$, and $\rho_{*}$ were approximately fixed as the electron collisionality $\nu_{e}^{*}$ was varied by a factor of 3 . If the strong favorable scaling of increased dimensionless confinement $\Omega_{i} \tau_{E} \propto B_{T} \tau_{E}$ with reduced collisionality holds at low collisionality, high fusion neutron fluxes and fluences could be achievable in very compact ST devices perhaps only $30-50 \%$ larger in major radius than existing ST devices, thereby potentially enabling a reduced size and cost ST-based Fusion Nuclear Science Facility (ST-FNSF). To improve the understanding of ST plasma properties at reduced collisionality, a major Upgrade to the NSTX is underway to span the next 
NSTX Upgrade Scenarios

\begin{tabular}{|c|c|c|c|c|c|c|c|c|c|c|c|c|c|c|}
\hline \multirow{3}{*}{$\begin{array}{c}\text { Scenario } \\
\text { Confinement scaling } \\
\mathrm{I}_{\mathrm{p}}[\mathrm{MA}]\end{array}$} & \multicolumn{2}{|c|}{\begin{tabular}{|c|} 
NSTX \\
Reference \\
\end{tabular}} & \multicolumn{2}{|c|}{$100 \% \mathrm{NICD}$} & \multicolumn{2}{|c|}{ Long-pulse } & \multicolumn{2}{|c|}{$\operatorname{Max} I_{p}$} & \multicolumn{2}{|c|}{ Max $I_{p}, P_{\text {heat }}$} & \multicolumn{2}{|c|}{$100 \%$ NICD } & \multicolumn{2}{|c|}{$\operatorname{Max} I_{p}$} \\
\hline & & & H98у2 & H98у2 & H98y2 & H98y2 & H98y2 & H98y2 & H98y2 & H98y2 & ST & ST & ST & ST \\
\hline & 1.0 & 1.0 & 0.75 & 0.75 & 0.90 & 0.90 & 2.00 & 2.00 & 2.00 & 2.00 & 1.25 & 1.25 & 2.00 & 2.00 \\
\hline $\mathrm{B}_{\mathrm{T}}$ [Tesla] & 0.45 & 0.45 & 1.00 & 1.00 & 0.75 & 0.75 & 1.00 & 1.00 & 1.00 & 1.00 & 1.00 & 1.00 & 1.00 & 1.00 \\
\hline Aspect ratio & 1.5 & 1.5 & 1.7 & 1.7 & 1.7 & 1.7 & 1.7 & 1.7 & 1.7 & 1.7 & 1.7 & 1.7 & 1.7 & 1.7 \\
\hline $\mathrm{R}_{0}[\mathrm{~m}]$ & 0.86 & 0.86 & 0.93 & 0.93 & 0.93 & 0.93 & 0.93 & 0.93 & 0.93 & 0.93 & 0.93 & 0.93 & 0.93 & 0.93 \\
\hline Elongation & 2.8 & 2.8 & 2.80 & 2.80 & 2.80 & 2.80 & 2.80 & 2.80 & 2.80 & 2.80 & 2.80 & 2.80 & 2.80 & 2.80 \\
\hline Greenwald fraction & 0.5 & 1.0 & 0.50 & 1.00 & 0.50 & 1.00 & 0.50 & 1.00 & 0.50 & 1.00 & 0.50 & 1.00 & 0.50 & 1.00 \\
\hline $\mathrm{n}_{\mathrm{e}}-\mathrm{bar}\left[10^{20} \mathrm{~m}^{-3}\right]$ & 0.52 & 1.03 & 0.37 & 0.73 & 0.44 & 0.88 & 0.98 & 1.96 & 0.98 & 1.96 & 0.61 & 1.22 & 0.98 & 1.96 \\
\hline $\mathrm{P}_{\mathrm{NB}}[\mathrm{MW}]$ & 6.0 & 6.0 & 10.0 & 10.0 & 5.0 & 5.0 & 10.0 & 10.0 & 15.0 & 15.0 & 6.0 & 6.0 & 6.0 & 6.0 \\
\hline $\mathrm{P}_{\mathrm{RF}}[\mathrm{MW}]$ & 0.0 & 0.0 & 0.0 & 0.0 & 0.0 & 0.0 & 0.0 & 0.0 & 6.0 & 6.0 & 0.0 & 0.0 & 0.0 & 0.0 \\
\hline$P_{\text {heat }}[M W]$ & 6.0 & 6.0 & 10.0 & 10.0 & 5.0 & 5.0 & 10.0 & 10.0 & 21.0 & 21.0 & 6.0 & 6.0 & 6.0 & 6.0 \\
\hline I flat-top time $[\mathrm{s}]$ & 1.0 & 1.0 & 5.0 & 5.0 & 10.0 & 10.0 & 5.0 & 5.0 & 1.0 & 1.0 & 5.0 & 5.0 & 5.0 & 5.0 \\
\hline$\tau_{\text {current-redistribution }}[\mathrm{s}]$ & 0.25 & 0.19 & 0.44 & 0.34 & 0.33 & 0.25 & 0.69 & 0.53 & 0.96 & 0.74 & 1.31 & 0.82 & 1.14 & 0.71 \\
\hline \# redistribution times & 4.0 & 5.2 & 11.3 & 14.7 & 30.4 & 39.6 & 7.3 & 9.5 & 1.0 & 1.4 & 3.8 & 6.1 & 4.4 & 7.0 \\
\hline Stored energy [MJ] & 0.29 & 0.29 & 0.51 & 0.39 & 0.30 & 0.29 & 0.84 & 0.97 & 1.14 & 1.25 & 0.88 & 0.84 & 1.09 & 1.15 \\
\hline$\beta_{\mathrm{N}}[\% \mathrm{mT} / \mathrm{MA}]$ & 5.4 & 5.5 & 5.9 & 4.5 & 3.8 & 3.8 & 3.7 & 4.2 & 5.0 & 5.4 & 6.1 & 5.8 & 4.7 & 5.0 \\
\hline$\beta_{\mathrm{T}}[\%]$ & 21.5 & 21.9 & 7.8 & 5.9 & 8.1 & 8.0 & 12.8 & 14.8 & 17.4 & 19.1 & 13.3 & 12.8 & 16.5 & 17.5 \\
\hline$q^{*}$ & 3.6 & 3.6 & 10.3 & 10.3 & 6.4 & 6.4 & 3.9 & 3.9 & 3.9 & 3.9 & 6.2 & 6.2 & 3.9 & 3.9 \\
\hline Fast-ion $\beta$ fraction & 0.33 & 0.14 & 0.62 & 0.35 & 0.37 & 0.15 & 0.19 & 0.07 & 0.25 & 0.10 & 0.25 & 0.10 & 0.12 & 0.04 \\
\hline$v_{e}^{*}\left[\times 10^{-2}\right]($ for $q=2)$ & 5.8 & 16.3 & 2.38 & 6.75 & 4.23 & 12.0 & 3.52 & 10.0 & 2.26 & 6.40 & 0.93 & 3.48 & 1.80 & 6.73 \\
\hline Bootstrap fraction & 0.36 & 0.47 & 0.66 & 0.87 & 0.45 & 0.59 & 0.33 & 0.44 & 0.41 & 0.55 & 0.81 & 0.93 & 0.46 & 0.53 \\
\hline NBI CD fraction & 0.06 & 0.02 & 0.34 & 0.14 & 0.10 & 0.04 & 0.07 & 0.03 & 0.12 & 0.05 & 0.20 & 0.07 & 0.07 & 0.03 \\
\hline Non-inductive fraction & 0.41 & 0.49 & 1.00 & 1.01 & 0.55 & 0.64 & 0.40 & 0.46 & 0.54 & 0.60 & 1.01 & 1.01 & 0.53 & 0.56 \\
\hline Ip ramp-up time [s] & 0.2 & 0.2 & 0.38 & 0.38 & 0.45 & 0.45 & 1.00 & 1.00 & 1.00 & 1.00 & 0.63 & 0.63 & 1.00 & 1.00 \\
\hline Ip ramp-down time [s] & 0.1 & 0.1 & 0.19 & 0.19 & 0.23 & 0.23 & 0.50 & 0.50 & 0.50 & 0.50 & 0.31 & 0.31 & 0.50 & 0.50 \\
\hline Total I duration [s] & 1.3 & 1.3 & 5.6 & 5.6 & 10.7 & 10.7 & 6.5 & 6.5 & 2.5 & 2.5 & 5.9 & 5.9 & 6.5 & 6.5 \\
\hline TF flat-top time [s] & 1.3 & 1.3 & 6.6 & 6.6 & 11.7 & 11.7 & 6.6 & 6.6 & 6.6 & 6.6 & 6.6 & 6.6 & 6.6 & 6.6 \\
\hline Fraction TF flat-top used & 0.97 & 0.97 & 0.84 & 0.84 & 0.91 & 0.91 & 0.98 & 0.98 & 0.38 & 0.38 & 0.90 & 0.90 & 0.98 & 0.98 \\
\hline Total $\mathrm{OH}$ flux [Wb] & 0.75 & 0.75 & 2.10 & 2.10 & 2.10 & 2.10 & 2.10 & 2.10 & 2.10 & 2.10 & 2.10 & 2.10 & 2.10 & 2.10 \\
\hline Ip ramp-up flux [Wb] & 0.37 & 0.37 & 0.30 & 0.30 & 0.36 & 0.36 & 0.80 & 0.80 & 0.80 & 0.80 & 0.50 & 0.50 & 0.80 & 0.80 \\
\hline Surface voltage [V] & 0.24 & 0.26 & 0.00 & 0.00 & 0.13 & 0.14 & 0.19 & 0.22 & 0.10 & 0.12 & 0.00 & 0.00 & 0.09 & 0.13 \\
\hline Total flat-top flux [Wb] & 0.38 & 0.38 & 1.80 & 1.80 & 1.74 & 1.74 & 1.30 & 1.30 & 1.30 & 1.30 & 1.60 & 1.60 & 1.30 & 1.30 \\
\hline Flat-top flux used [Wb] & 0.24 & 0.26 & 0.00 & 0.0 & 1.33 & 1.40 & 0.95 & 1.09 & 0.10 & 0.12 & 0.0 & 0.0 & 0.44 & 0.67 \\
\hline Fraction $\mathrm{OH}$ flux used & 0.81 & 0.84 & 0.14 & 0.14 & 0.81 & 0.84 & 0.83 & 0.90 & 0.43 & 0.44 & 0.24 & 0.24 & 0.59 & 0.70 \\
\hline Power fraction to divertor & 0.5 & 0.5 & 0.50 & 0.50 & 0.50 & 0.50 & 0.50 & 0.50 & 0.50 & 0.50 & 0.50 & 0.50 & 0.50 & 0.50 \\
\hline$R_{\text {strike-point }}[\mathrm{m}]$ & 0.40 & 0.40 & 0.50 & 0.50 & 0.50 & 0.50 & 0.50 & 0.50 & 0.50 & 0.50 & 0.50 & 0.50 & 0.50 & 0.50 \\
\hline SOL heat-flux width $[\mathrm{cm}]$ & 0.90 & 0.90 & 1.43 & 1.43 & 1.07 & 1.07 & 0.30 & 0.30 & 0.30 & 0.30 & 0.63 & 0.63 & 0.30 & 0.30 \\
\hline Poloidal flux expansion & 22.0 & 22.0 & 20.0 & 20.0 & 20.0 & 20.0 & 62.0 & 62.0 & 58.0 & 58.0 & 20.0 & 20.0 & 37.0 & 37.0 \\
\hline Peak heat flux $\left[\mathrm{MW} / \mathrm{m}^{2}\right]$ & 6.0 & 6.0 & 5.6 & 5.6 & 3.7 & 3.7 & 8.6 & 8.6 & 13.9 & 13.9 & 7.6 & 7.6 & 8.7 & 8.7 \\
\hline Time to $\mathrm{T}_{\mathrm{PFC}}=1200^{\circ} \mathrm{C}[\mathrm{s}]$ & 13.8 & 13.8 & 16.1 & 16.1 & 35.8 & 35.8 & 6.7 & 6.7 & 2.6 & 2.6 & 8.7 & 8.7 & 6.6 & 6.6 \\
\hline Fraction of $T_{\mathrm{PFC}}$ limit & 0.09 & 0.09 & 0.35 & 0.35 & 0.30 & 0.30 & 0.97 & 0.97 & 0.96 & 0.96 & 0.68 & 0.68 & 0.98 & 0.98 \\
\hline
\end{tabular}

TABLE I

PARAMETERS OF REPRESENTATIVE NSTX-U SCENARIOS.

factor of 3-6 reduction in collisionality while also extending other NSTX physics regimes and capabilities such as noninductive current ramp-up and sustainment.

\section{Physics Requirements And EngineERING DESIGN}

\section{A. Centerstack, PF coils, Structural Enhancements}

Scoping studies of NSTX-U operating scenarios are important for identifying the Upgrade performance requirements to achieve the physics research goals. Using 0-D scaling analysis benchmarked against NSTX experimental data, Table I contains parameters of interest for an NSTX reference discharge and for several representative NSTX-U scenarios assuming two confinement scalings: ITER IPB98(y,2) H-mode scaling and an ST-specific confinement scaling based on NSTX and MAST scalings. Further, parameters are shown for two
TF, OH, and Plasma Current Units: $I_{\mathrm{OH}}$ and $\mathrm{I}_{\mathrm{TF}}[\mathrm{kA}], \mathrm{I}_{\mathrm{P}}[\mathrm{kA} / 10]$

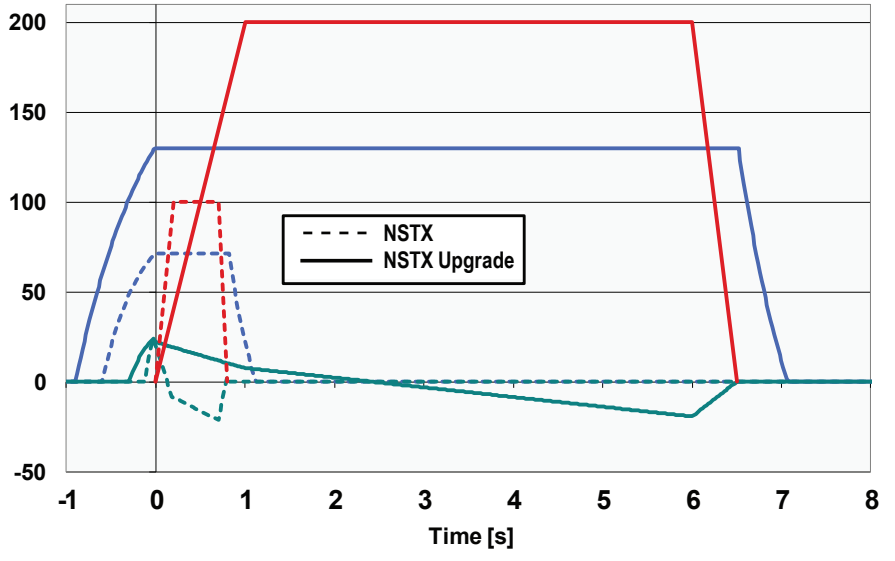

Fig. 2. Comparison of toroidal field (TF), ohmic heating (OH), and plasma current waveforms for plasmas operated at the maximum toroidal field capabilities of NSTX (0.55T) and NSTX Upgrade (1T).

assumed plasma densities: 0.5 and $1.0 \times$ the Greenwald density limit. The representative NSTX-U operating scenarios include: $100 \%$ non-inductive current drive, partially-inductively-driven long-pulse, high/maximum plasma current, and high current plus high heating power. These scenarios address critical issues for the ST, namely: non-inductive sustainment, the establishment of equilibrated integrated scenarios, ST confinement and stability scaling and understanding, and high-power and particle exhaust understanding and mitigation, respectively.

With respect to collisionality reduction relative to the NSTX reference scenario, a factor of 5-6 decrease in collisionality is projected to be achievable at fixed Greenwald fraction by operating at 1T, 1.25MA, and 6MW assuming ST confinement scaling (right-most green columns). This strong decrease in collisionality at current and power values similar to the present NSTX is the result of the strong toroidal field dependence of the ST confinement scaling. In contrast, if ITER H-mode confinement scaling is assumed, only a factor of 2-3 reduction in collisionality would be achieved even with $2 \times$ higher current and/or power (red and left-most green columns) due to the weak toroidal field dependence of the ITER confinement scaling. Thus, the ability to double the toroidal field, plasma current, and heating power is needed to reduce the uncertainty in the scaling of ST energy confinement as plasma temperatures are increased further toward the values of next-step STs.

The required coil and plasma current pulse duration is another important consideration, and here the current redistribution time is generally the longest profile relaxation timescale. On NSTX, 3-4 current redistribution times are typically required to achieve an equilibrated q profile, and if confinement continues to scale nearly inversely with collisionality at low collisionality, the current redistribution time could increase as much as a factor of 5 (compare right-most green columns to NSTX reference). Thus, to ensure similar profile relaxation in the Upgrade, the current and TF flat-top durations must increase by a factor of 5 to $5 \mathrm{~s}$ and $6.6 \mathrm{~s}$ respectively. 
To assess ST physics at $2 \times$ higher TF and similar safety factor q, the plasma current must double from 1MA to 2MA. Sufficient loop voltage must also be provided for any needed inductive current drive. The operating scenario analysis indicates that 2MA plasmas at intermediate power levels (10MW) assuming ITER confinement scaling and Greenwald fraction of 1 require the highest surface voltage $(0.2-0.25 \mathrm{~V})$ for sustainment, and these scenarios set the required $\mathrm{OH}$ flux to sustain a $5 \mathrm{~s} \mathrm{I}_{\mathrm{P}}$ flat-top. Including the breakdown+rampup flux required in addition to the current flat-top flux, the total $\mathrm{OH}$ flux required increases by approximately a factor of 3 to $2.1 \mathrm{~Wb}$. Finally, the ability to access normalized and toroidal beta values in NSTX-U comparable to those achieved in NSTX is also important for assessing the stability and transport physics dependence on beta and $\nu^{*}$ at reduced $\nu^{*}$. For the ST confinement scaling, access to high temperature and beta is achievable with heating power comparable to that in NSTX, but for ITER H-mode scaling, substantially more power (factor of 2-3 $\times$ higher) is required to achieve similar $\beta$ values at similar safety factor $q^{*}$ (see middle yellow and red columns in Table I).

To summarize the combination of requirements above, the Upgraded NSTX device should: double $B_{T}$ at $\mathrm{R}=0.93 \mathrm{~m}$ from $0.5 \mathrm{~T}$ to $1 \mathrm{~T}$ and increase the TF flat-top to $6-7 \mathrm{~s}$, double $I_{P}$ from $1 \mathrm{MA}$ to $2 \mathrm{MA}$ and provide a $5 \mathrm{~s}$ flat-top at full current, double the neutral beam injection (NBI) heating power from $P_{N B I}=$ $5 \mathrm{MW}$ to $10 \mathrm{MW}$ and sustain it for $5 \mathrm{~s}$, and nearly triple the $\mathrm{OH}$ flux from $0.75 \mathrm{~Wb}$ to $2.1 \mathrm{~Wb}$. Representative waveforms for the NSTX and NSTX Upgrade currents are shown in Figure 2 and illustrate the substantial increase in device performance.

An important feature of the NSTX device design is the ability to remove the center-stack (CS) independent of the vacuum vessel and the external PF and TF magnets. Thus, Upgrade performance requirements can potentially be met by replacing the present CS with a new larger CS thereby providing more cross-sectional area and conductor to carry the TF current and also providing increased $\mathrm{OH}$ flux. The increased size of the new CS is shown graphically in Figure 3a by the red outline overdrawn on the present CS. Figure $3 b$ shows the doubling of the TF conductor diameter which enables the doubling of $\mathrm{TF}$ current with $5 \times$ longer pulses. The $\mathrm{OH}$ coil diameter also nearly doubles in the new CS, but the number of $\mathrm{OH}$ turns is decreased by $20 \%$ to increase the conductor cross-section and cooling hole diameter to enable inter-shot cool-down times under 15 minutes. As shown in Figure 3c, this larger $\mathrm{CS}$ incorporates the larger $\mathrm{TF}$ and $\mathrm{OH}$ while also including three upper and lower divertor PF coils PF1A,B,C (compared to two/one PF coils in the lower/upper divertor of NSTX) and also providing an insulating break for biasing the CS casing relative to the vessel for Coaxial Helicity Injection (CHI) current start-up. This larger outer diameter (OD) CS increases the minimum aspect ratio of fully limited plasmas from $\mathrm{A}=1.3$ to 1.5 . As a result, diverted plasmas will typically have $\mathrm{A} \geq 1.6$. While this aspect ratio is larger than the present NSTX, it is comparable to the optimal aspect ratio identified in ST-FNSF and ARIES-ST reactor studies.

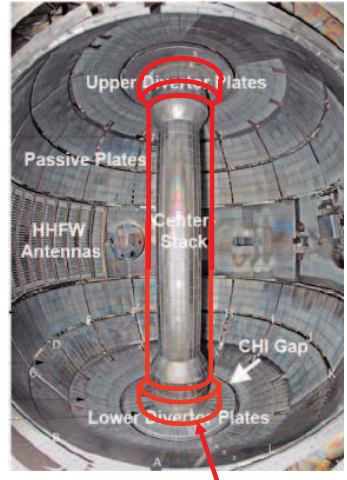

(a) Outline of new center-stack (CS)

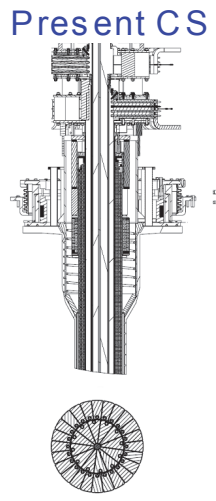

(b)

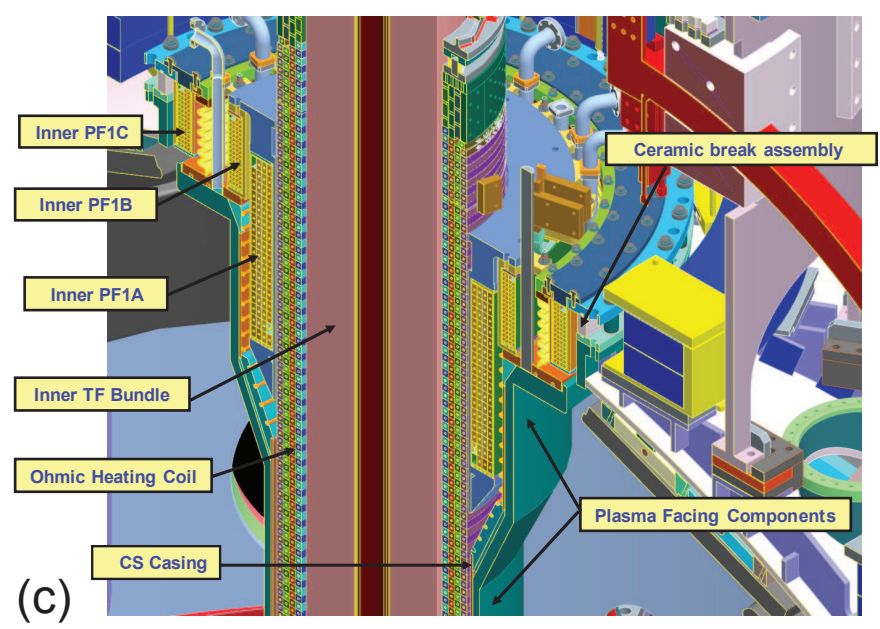

Fig. 3. (a) Outlines and (b) cross-sections of the present and new centerstack for comparing the TF conductor diameters, and (c) detailed cross-section of the Upgrade center-stack showing the TF, OH, and divertor PF coils, and the $\mathrm{CHI}$ insulator and PFC boundaries.
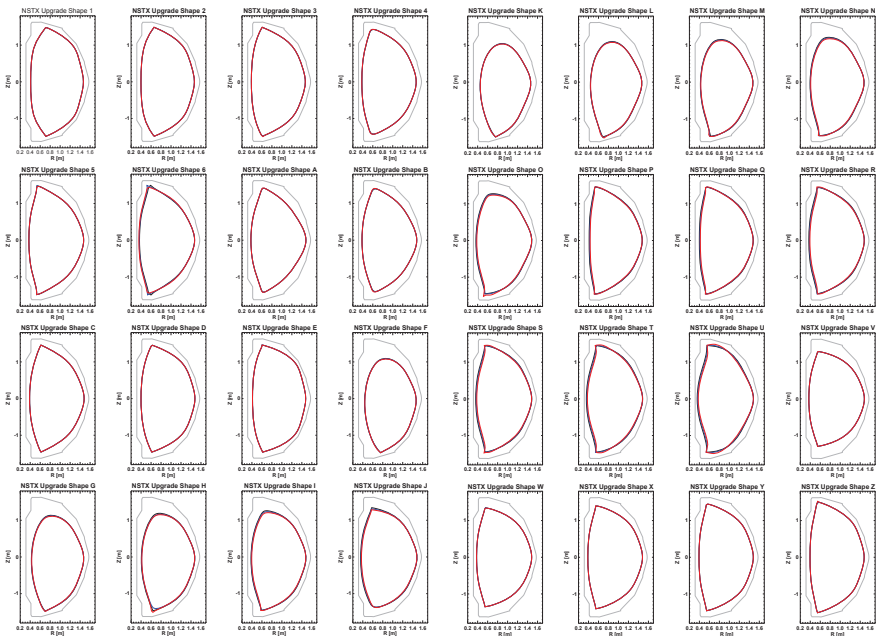

Fig. 4. Plasma boundaries of free-boundary equilibria used for assessing PF coil current requirements in NSTX Upgrade. Each plot is a superposition of three boundary plots, i.e. one for each $\mathrm{OH}$ power supply current state assessed: $0 \mathrm{kA}$ and $\pm 24 \mathrm{kA}$. 


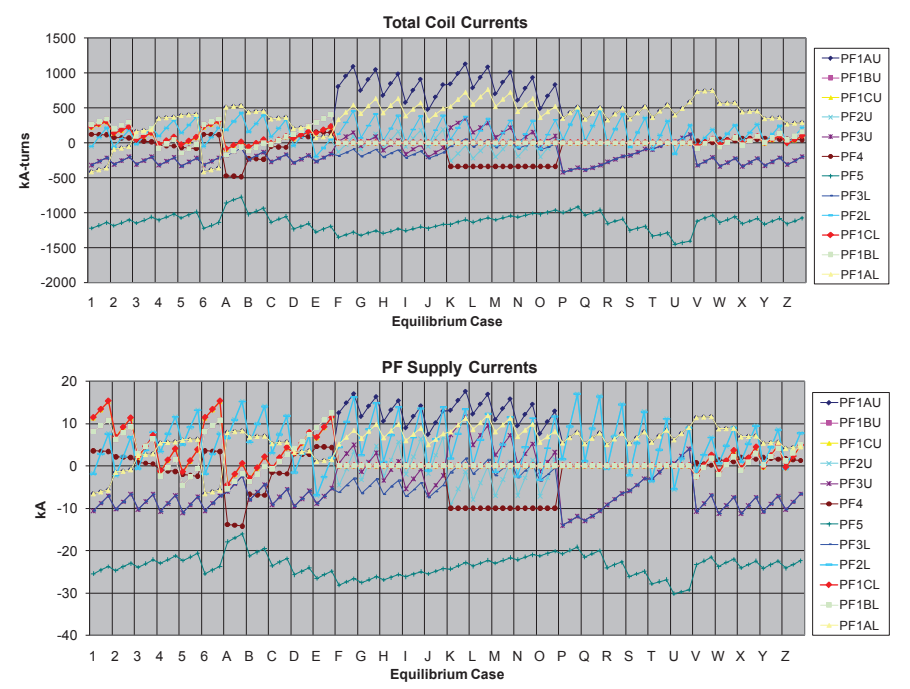

Fig. 5. Total coil current (top) and power supply current (bottom) required for each of the 96 reference 2MA Upgrade equilibria.
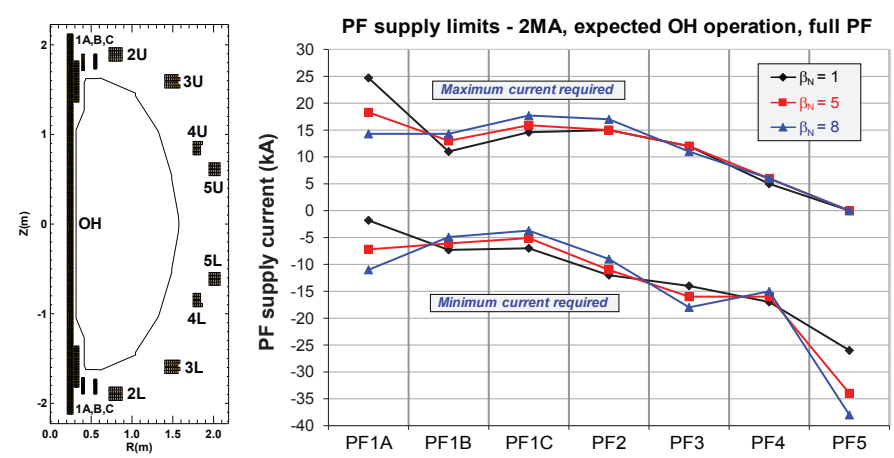

Fig. 6. (Left) $\mathrm{PF}$ and $\mathrm{OH}$ coil current locations and sizes and limiter boundary and (right) minimum and maximum PF coil current vs $\beta_{N}$.

To enable engineering design of the upgrade, systematic free-boundary equilibrium calculations have been performed to determine the Upgrade poloidal field requirements. The design range spans aspect ratio $\mathrm{A}=1.6$ to 1.9 , internal inductance $l_{i}=$ 0.4 to 1.1 , elongation $\kappa=2.1$ to 2.9 , triangularity $\delta=0.2$ to 0.7 , squareness $\zeta=-0.15$ to 0.12 , magnetic balance $\delta_{R s e p}=-1.5$ to $0 \mathrm{~cm}$, normalized pressure $\beta_{N}=1,5$, and 8 , and $\mathrm{OH}$ solenoid current $=0$ and $\pm 24 \mathrm{kA}$ (power supply limits) to determine the divertor poloidal field (PF) needed for cancellation of $\mathrm{OH}$ leakage flux. Figure 4 shows the 32 plasma boundaries of free-boundary equilibria used for assessing the PF coil current requirements for 2MA NSTX Upgrade plasmas. Each boundary shown is actually a plot of three plasma boundaries for each state of the $\mathrm{OH}$ coil current described above, and this set of 96 equilibria provides the set of configurations used for the detailed engineering design of the Upgrade. The PF coil currents for each configuration are shown in Figure 5 for 2MA plasmas with $\beta_{N}=5$, and the PF coil locations and sizes and the minimum and maximum currents as a function of $\beta_{N}$ are shown in Figure 6. As is evident from Figure 6, the most substantial change in coil current for varied $\beta_{N}$ is for the vertical field coil PF5.

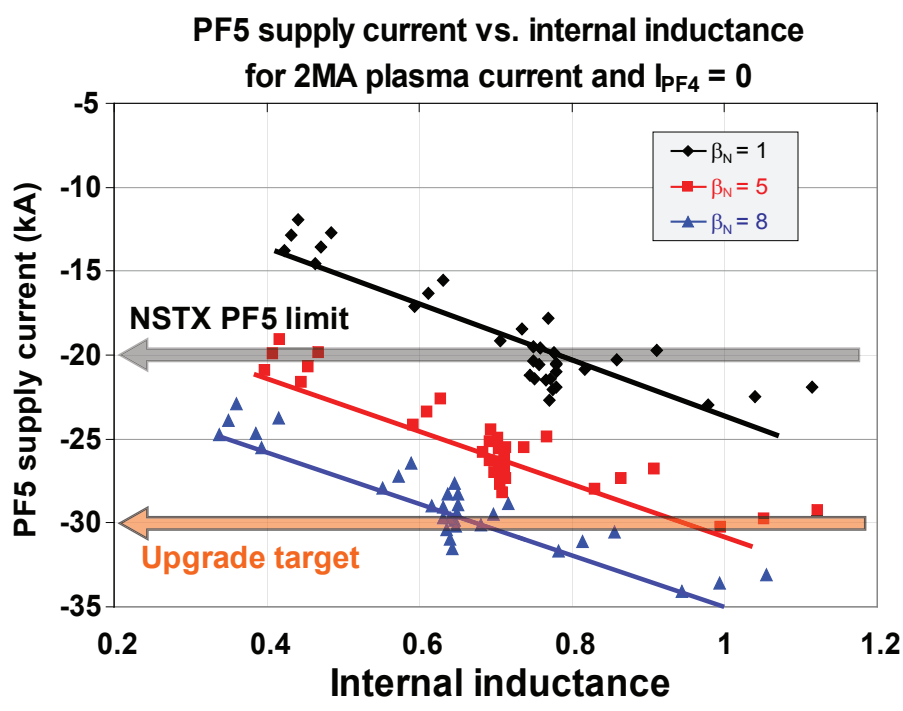

Fig. 7. PF5 vertical field coil current required to support 2MA plasmas as a function of internal inductance and normalized beta.

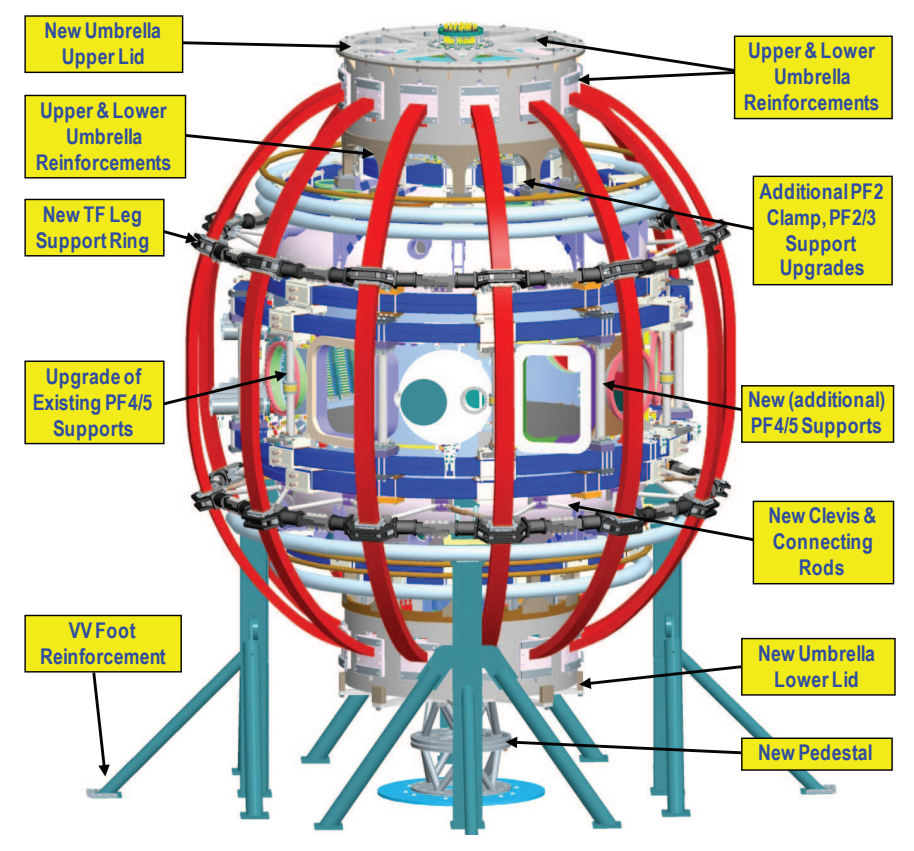

Fig. 8. Vessel reinforcements and other modifications required for handling increased forces associated with higher field and current of the Upgrade.

In addition to accounting for variation in the plasma shape, the PF coil current requirements have also been assessed as a function of plasma current profile (internal inductance) and normalized beta for 2MA, 1T plasmas. The plasma inductance and beta primarily influence the required vertical field (PF5) coil current, and as shown in Figure 7, increased inductance and beta both increase the required vertical field. The Upgrade design will increase the maximum PF5 current by $50 \%$ from $20 \mathrm{kA}$ to $30 \mathrm{kA}$ nominal maximum operating current. This enhancement will enable 2MA equilibria with $\beta_{N}$ up to 5 at $l_{i}$ $=1$ and $\beta_{N}$ up to 8 at $l_{i}=0.6$, and this increased vertical field capability supports all scenarios used for the Upgrade design. 
(a)

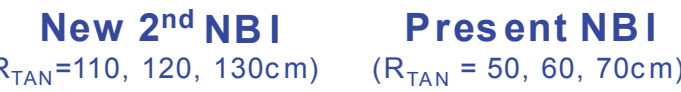

(b)
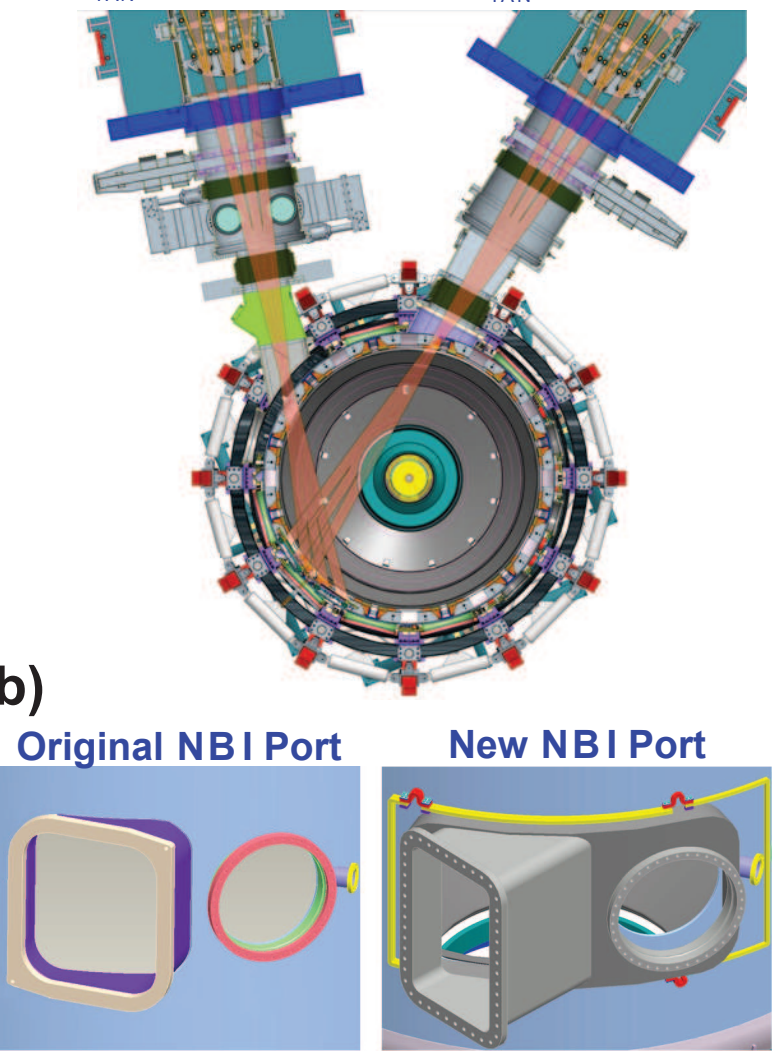

Fig. 9. (a) Injection geometry of present and new 2nd NBI, and (b) modification of the present NBI port to a new NBI port cap to enable the more tangential injection.

Doubling the TF and plasma current increases the forces on the coil supports and vacuum vessel up to a factor of 4 , and substantial analysis and design has been performed to provide structural reinforcement against the increased loads. As shown in Figure 8, these modifications include a new flexible umbrella upper lid to allow $\mathrm{OH} / \mathrm{TF}$ vertical thermal expansion while transferring torsional loads of the CS to the outer vessel, new TF support rings and clevises to transfer torsional loads on the TF coils to the vacuum vessel, new and upgraded vertical field coil (PF4 and PF5) separator struts to take increased inter-coil forces, and a new pedestal on which the CS is supported.

\section{B. 2nd Neutral Beam Injector}

Beyond the new CS and ex-vessel structural enhancements, a 2nd neutral beam from TFTR has been chosen to provide the factor of 2 increase in auxiliary heating and current drive power for NSTX Upgrade, as this is presently the most mature and capable technology applicable to ST plasma parameters. The addition of a 2nd NBI not only serves to increase the auxiliary heating power to access reduced $\nu^{*}$, but also has increased tangency radius of injection $R_{t a n}$ as shown in Figure 9a to substantially increase current drive efficiency for non-inductive current ramp-up and sustainment. Achieving this increased tangency radius of injection requires a significant
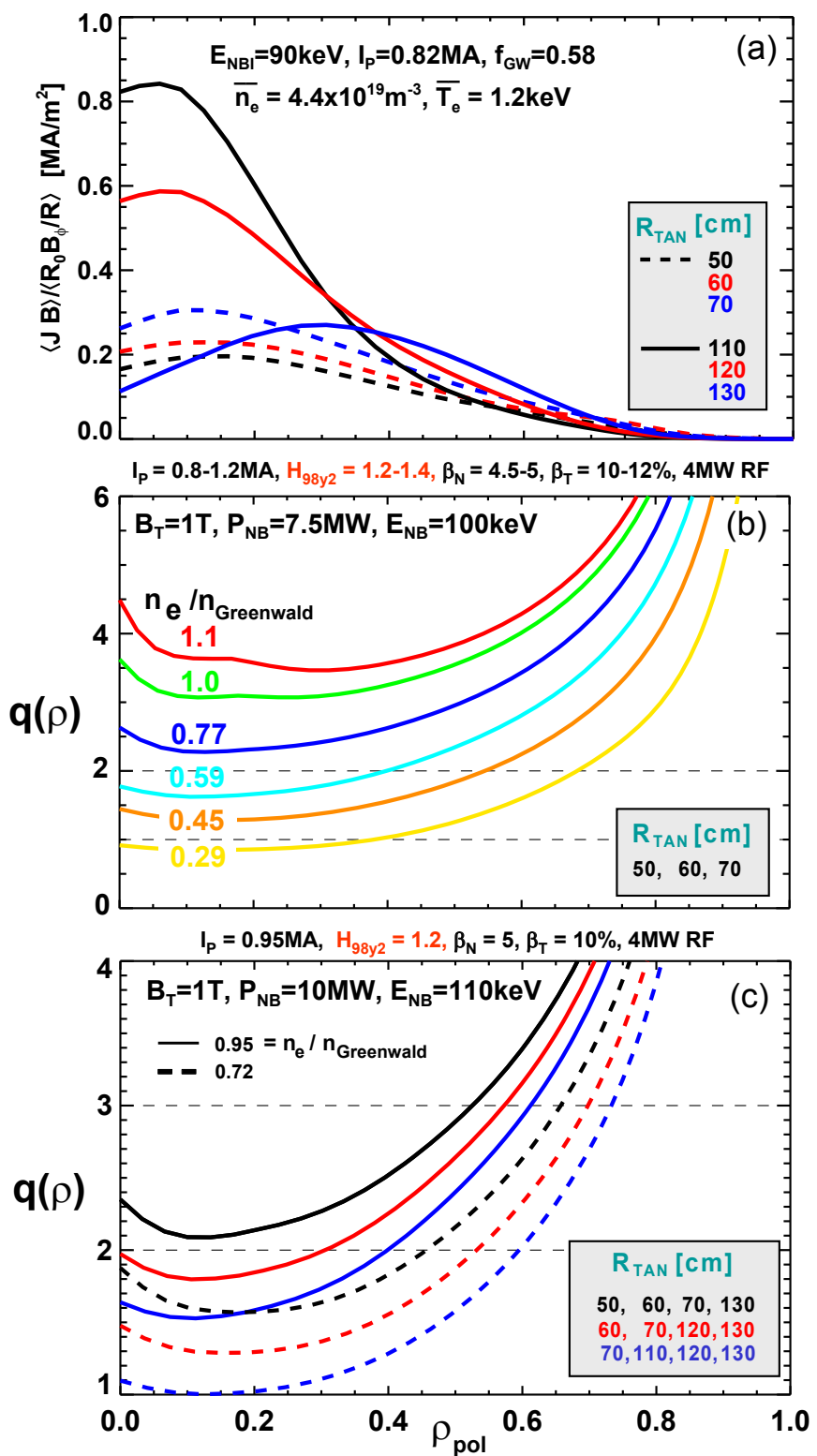

Fig. 10. (a) Comparison of parallel current density profiles for existing (dashed) and 2nd (solid) NBI sources, and q profile controllability vs. density for (b) existing and (c) additional NBI sources.

modification to the NSTX vacuum vessel with the cutting of a large opening in the vessel wall for the installation of a new NBI port cap as shown in Figure 9b.

A critical element of ST research in support of steadystate operation is to increase the $70 \%$ non-inductive fraction sustained in NSTX [5] to fully-non-inductively sustained plasmas. Future ST-FNSF facilities are projected to rely heavily on NBI current drive (NBICD) to drive as much as 50\% of the plasma current with the remainder provided by neoclassical bootstrap current. Reduced collisionality in NSTX Upgrade will help increase the NBI current drive efficiency to increase the non-inductive fraction, but additional current drive is still required. TRANSP simulations indicate that more tangential NBI can increase NBICD efficiency by up to a factor of two - from $I_{N B I C D} / P_{I N J}=30-40 \mathrm{kA} / \mathrm{MW}$ for the inner-most $R_{t a n}=50 \mathrm{~cm}$ to up $70-80 \mathrm{kA} / \mathrm{MW}$ for $R_{t a n}=1.1$ - 
$1.3 \mathrm{~m}$, i.e. outboard of the magnetic axis (see Figure 10a). Further, for current profile control, variation of the NBICD deposition profile is needed. As shown in Figure 10a, the NBICD deposition profile depends only weakly on $R_{t a n}$ for the present NBI $\left(R_{t a n}=50,60,70 \mathrm{~cm}\right)$. In contrast, for the more tangential injection of the 2nd NBI in the Upgrade, $R_{t a n}$ $=110,120,130 \mathrm{~cm}$ can vary the injected NBICD parallel current density from centrally peaked to peaked off-axis. As shown in Figure 10b, using only the existing NBI with the CS upgrade, full-power NBI (7.5MW) + 4MW HHFW heating is needed to support $100 \%$ non-inductive operation, and the only means of $q$ control is $q_{\min }$ variation through the plasma density (i.e. CD efficiency). Further, such scenarios require $H_{98}=1.2-1.4$ and would be limited to $1.5 \mathrm{~s}$ duration by NBI ion dump operating limits. $H_{98}=1.3-1.4$ has been obtained transiently in NSTX, but sustaining $H_{98}=1.15-1.2$ is only now beginning to be achieved with $\mathrm{Li}$ conditioning [6] in ELM-free conditions in NSTX with a goal of extending this enhanced confinement to small-ELM regimes. With the addition of the 2nd NBI of the Upgrade, Figure 10c shows that higher NBI power (10MW vs. $7.5 \mathrm{MW})$ can reduce the required confinement to $H_{98}=1.2$ for $100 \%$ non-inductive scenarios and also enables control of $q_{\min }$ with $\Delta q_{\min }=0.6$ by varying the NBI source mix at fixed density. Further, scenarios with $n_{e} / n_{\text {Greenwald }}=0.7-1$ exist with $q_{\min }$ varying from 1 to above 2 with important implications for stability and transport research. All of the above scenarios operate above the $n=1$ no-wall stability limit and require stabilization of the resistive wall mode as is common for advanced scenarios on NSTX [7].

TRANSP calculations have also been carried out for $100 \%$ non-inductive current drive using all 6 NBI sources at 1MA and 1T and by optimizing the outer gap to optimize the current drive profile. As shown in Figure 11a, 100\% non-inductive current drive is possible for a wide range of normalized density values with ITER $\mathrm{H}$-mode confinement multiplier $H_{98}=1$ 1.05. As shown in Figure $11 \mathrm{~b}, q_{\min }$ can be varied by a factor of 3 by varying the normalized density. As shown in the figure, the $q_{\min }$ values can be increased well above 2 by operating at high normalized density with important implications for kink/RWM stability and for the avoidance of $m / n=2 / 1$ neoclassical tearing modes.

Future ST-FNSF facilities are also projected to operate without a central solenoid, making non-inductive ramp-up (with reliance on NBI heating and CD) a critical element of ST research. Present NSTX research is pursuing noninductive formation of plasma current using Coaxial Helicity Injection (CHI) [8] to form a closed-flux plasma of 0.2$0.3 \mathrm{MA}$ to be heated and sustained by high-harmonic fastwaves in a high bootstrap-current-fraction $\mathrm{H}$-mode plasma. As shown in Figure 12a, CHI has been successfully coupled to high-confinement inductively-driven plasmas with an early current savings of $150-200 \mathrm{kA}$ relative to OH-only start-up. As shown in Figure 12b, this corresponds to plasma poloidal flux formation by $\mathrm{CHI}$ of $50 \mathrm{mWb}$. The plasmas compared in Figure 12 are chosen to have a similar shape and $l_{i}$ value and evolution to illustrate the current and flux savings from CHI.
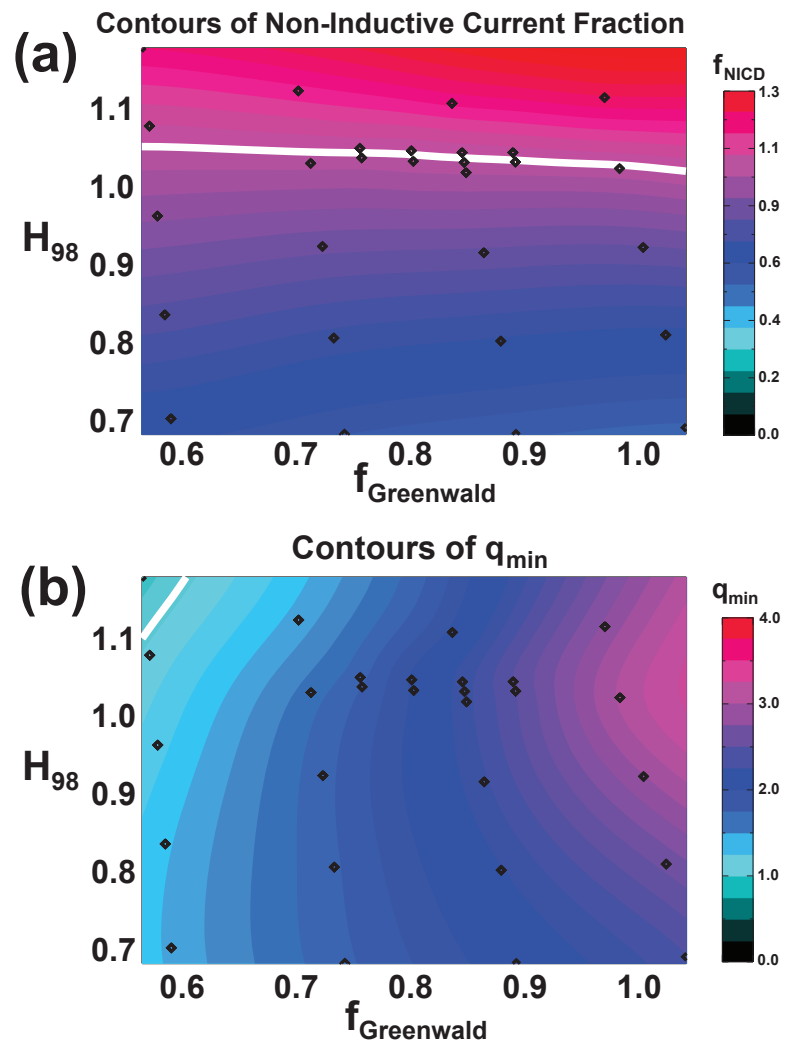

$A=1.75, \kappa=2.8, B_{T}=1.0 T, I_{P}=1.0 \mathrm{MA}$ $90 \mathrm{kV}$ Beams $\quad R_{\tan }=[50,60,70,110,120,130] \mathrm{cm}$

Fig. 11. Contours of (a) non-inductive current fraction and (b) minimum safety factor $q_{\min }$ versus $f_{\text {Greenwald }}$ and ITER H-mode confinement multiplier $\mathrm{H}_{98}$ for 1MA plasmas with 12MW of NBI heating.
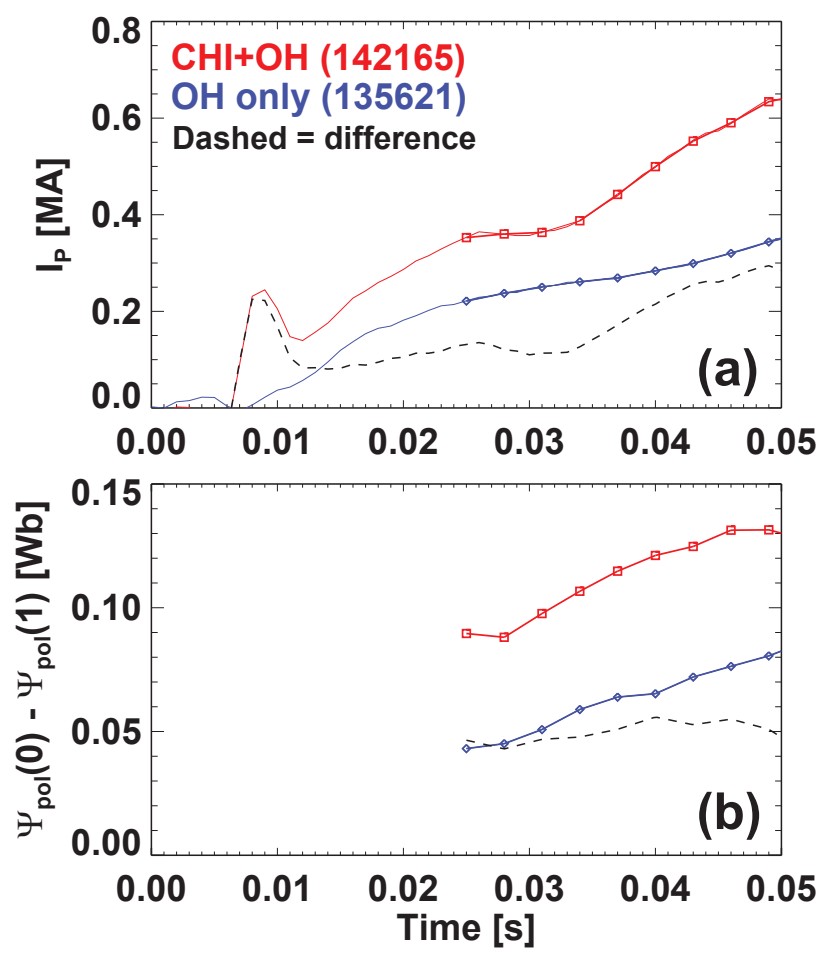

Fig. 12. (a) Plasma current savings and (b) poloidal flux savings from CHI coupled to induction in NSTX start-up plasmas. 

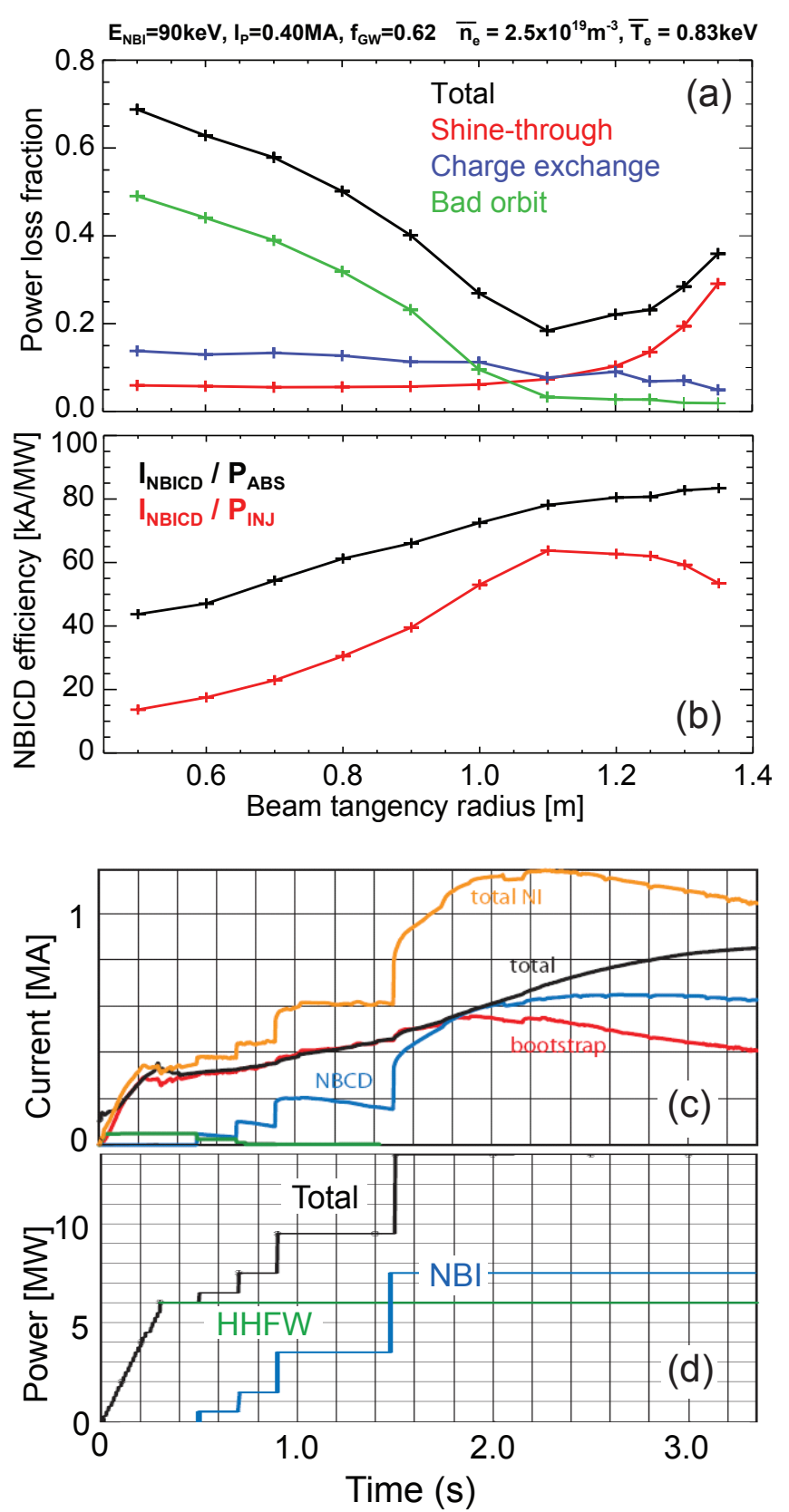

Fig. 13. Predicted (TRANSP) (a) power loss fraction and (b) current drive efficiency vs. tangency radius, and simulated (TSC) (c) non-inductive currents and (d) heating power for non-inductive ramp-up.

CHI current formation projects favorably to the Upgrade with a scaling linear in toroidal field. Thus, one can expect $\mathrm{CHI}$ to be able to generate $300-400 \mathrm{kA}$ of closed-flux current in NSTX Upgrade by operating at $1 \mathrm{~T}$.

A very important benefit of more tangential NBI is the ability to heat and drive current in lower plasma current targets. As shown in Figure 13a for low $I_{p}=0.4 \mathrm{MA}$ target plasmas, the NBI power losses (presently dominated by bad-orbit losses) are predicted to be reduced by up to a factor of 3 with the increased $R_{t a n}$ of the 2 nd NBI of the Upgrade. As shown in Figure 13b, this translates into a factor of 3 increase in $\mathrm{CD}$ efficiency of up to $60 \mathrm{kA} / \mathrm{MW}$ for the $2 \mathrm{nd}$ NBI. As is evident from the Figure, the tangency radii of the 2nd NBI

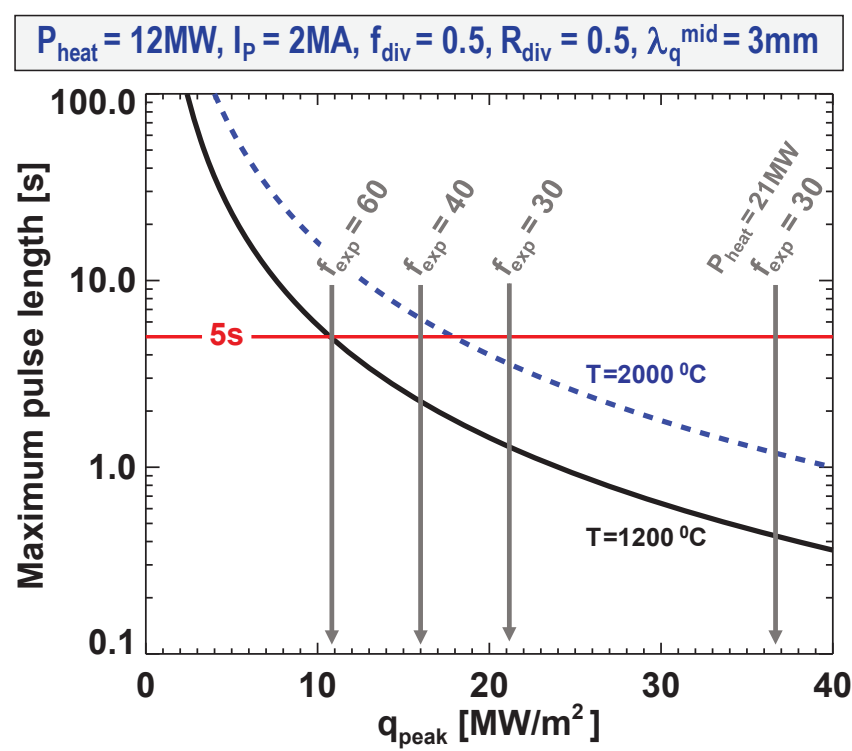

Fig. 14. Projected NSTX Upgrade pulse-length limits versus peak divertor heat flux for two divertor carbon PFC temperature values.

are close to the optimal values (by design) for maximizing the NBICD at low plasma current. As shown in Figure 13c$\mathrm{d}$, TSC simulations indicate this 400-450kA of NBICD is sufficient to non-inductively over-drive a $0.4 \mathrm{MA}$ target plasma to a $0.8-0.9 \mathrm{MA}$ flat-top current. Thus, by operating at $1 \mathrm{~T}$ and combining CHI projected current formation of 300-400kA to NBI current ramp-up with the 2nd NBI, NSTX Upgrade is very well equipped to study non-inductive current formation and ramp-up as needed for an ST-FNSF.

\section{Divertor POWER HANDLING}

While the compactness of the ST is beneficial for achieving high neutron wall loading for FNS, the ST divertor heat fluxes can also be high and challenge PFC power handling capabilities. Of particular concern is the strong inverse scaling of the heat-flux width with plasma current, and recent assessments of the divertor heat flux scaling in NSTX project to peak divertor heat fluxes over $20 \mathrm{MW} / \mathrm{m}^{2}$ in the Upgrade even assuming high poloidal flux expansions of 30 [9]. As shown in Figure 14, the peak heat flux must be limited to $10 \mathrm{MW} / \mathrm{m}^{2}$ to enable $5 \mathrm{~s}$ operation with the inertially/radiatively cooled ATJ graphite PFCs planned for the Upgrade. As indicated in Figure 14, 2MA plasmas are projected to have $3 \mathrm{~mm}$ mid-plane scrapeoff-layer (SOL) heat-flux widths. Utilizing upper/lower powersplitting but not accounting for any radiation/detachment or strike-point sweeping, poloidal flux expansions of 60 are required to achieve peak heat-flux near $10 \mathrm{MW} / \mathrm{m}^{2}$ for $P_{\text {heat }}$ $=12 \mathrm{MW}$ in $2 \mathrm{MA}$ plasmas.

Very high flux expansions of 40-60 have recently been demonstrated in NSTX utilizing a "snowflake" [10] divertor as shown in Figure 15a. In order to support this and other future high-flux-expansion divertors such as the "Super-X" [11] (possible with additional in-vessel PF coils not part of the present Upgrade), additional divertor PF coils have been incorporated into the Upgrade CS design as shown in Figure 3c. In particular, a third divertor PF coil (PF1C) will be added to 


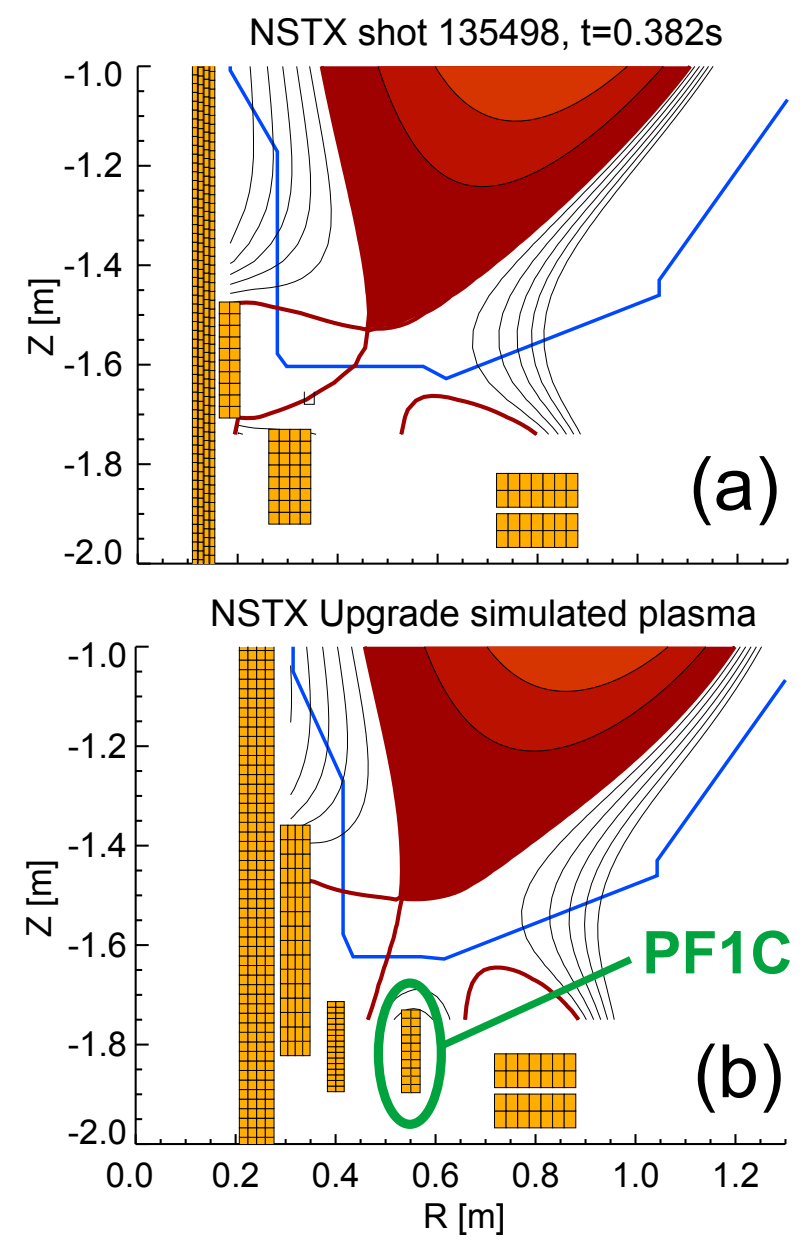

Fig. 15. (a) Snowflake divertor in NSTX and (b) NSTX Upgrade.

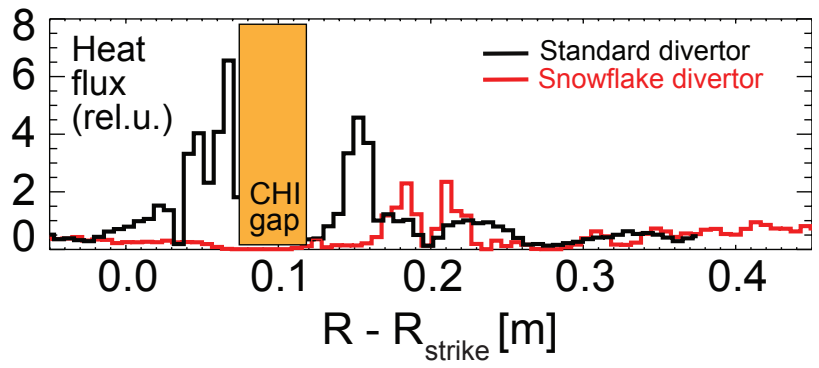

Fig. 16. Peak heat flux in a standard divertor configuration in NSTX (black) compared to the snowflake divertor (red).

the CS as shown in Figure 15b to support the snowflake and to improve flux expansion and strike-point control generally. Recently, the snowflake divertor has demonstrated large (factor of 3) reductions in peak heat flux as shown in Figure 16, and also up to a 50\% reduction in carbon impurity production [12]. Thus, the snowflake divertor projects favorably to mitigating high divertor heat fluxes projected for NSTX Upgrade and in particular for enabling flat-top durations up to $5 \mathrm{~s}$ at $2 \mathrm{MA}$.

\section{CONCLUSiON}

The combination of a new CS and 2nd more tangentially injecting NBI will provide substantial new capabilities to advance ST research in support of FNSF in the areas of: transport, stability, non-inductive plasma start-up, sustainment, current profile control, and plasma-material interactions. The engineering design is now complete for the new CS, exvessel structural enhancements, and 2nd NBI modifications. The NSTX Upgrade outage is presently scheduled to begin in April 2012 and to be completed at the end of 2014.

\section{ACKNOWLEDGMENT}

This work was supported in part by the U.S. DOE Contract Number DE-AC02-09CH11466.

\section{REFERENCES}

[1] Y.-K. M. Peng, P. J. Fogarty, T. W. Burgess, D. J. Strickler, B. E. Nelson, J. Tsai, C. A. Neumeyer, R. Bell, C. Kessel, J. Menard, D. Gates, B. LeBlanc, D. Mikkelsen, E. Fredrickson, L. Grisham, J. Schmidt, P. Rutherford, S. Sabbagh, , A. Field, A. Sykes, I. Cook, O. Mitarai, and Y. Takase, "A component test facility based on the spherical tokamak," Plasma Phys. and Contr. Fus., vol. 47, p. B263, November 2005.

[2] Y.-K. M. Peng, T. W. Burgess, A. J. Carroll, C. L. Neumeyer, J. M. Canik, M. J. Cole, W. D. Dorland, P. Fogarty, L. Grisham, D. Hillis, Y. Katoh, K. Korsah, M. Kotschenreuther, R. La Haye, S. Mahajan, R. Majeski, B. E. Nelson, B. D. Patton, D. A. Rasmussen, S. A. Sabbagh, A. C. Sontag, R. E. Stoller, C.-C. Tsai, P. Valanju, J. C. Wagner, and G. L. Yoder, "Remote handling and plasma conditions to enable fusion nuclear science R\&D using a component testing facility," Fusion Sci. Technol., vol. 56, p. 957, August 2009.

[3] S. M. Kaye, F. M. Levinton, D. Stutman, K. Tritz, H. Yuh, M. G. Bell, R. Bell, C. W. Domier, D. Gates, W. Horton, J. Kim, B. P. LeBlanc, N. C. L. Jr., R. Maingi, E. Mazzucato, J. Menard, D. Mikkelsen, D. Mueller, H. Park, G. Rewoldt, S. A. Sabbagh, D. R. Smith, and W.Wang, "Confinement and local transport in the National Spherical Torus Experiment (NSTX)," Nucl. Fus., vol. 47, p. 499, 2007.

[4] M. Valovic, R. Akers, G. Cunningham, L. Garzotti, B. Lloyd, D. Muir, A. Patel, D. Taylor, M. Turnyanskiy, and M. W. and the MAST team, "Scaling of h-mode energy confinement with $I_{p}$ and $B_{T}$ in the MAST spherical tokamak," Nucl. Fus., vol. 49, p. 075016, 2009.

[5] S. P. Gerhardt, E. Fredrickson, D. Gates, S. Kaye, J. Menard, M. G. Bell, R. E. Bell, B. P. L. Blanc, H. Kugel, S. A. Sabbagh, and H. Yuh, "Calculation of the non-inductive current profile in high-performance NSTX plasmas," Nucl. Fus., vol. 51, p. 033004, 2011.

[6] R. Maingi, R. E. Bell, J. M. Canik, S. P. Gerhardt, S. M. Kaye, B. P. LeBlanc, T. H. Osborne, M. G. Bell, E. D. Fredrickson, K. C. Lee, J. E. Menard, J.-K. Park, S. A. Sabbagh, and N. team, "Triggered confinement enhancement and pedestal expansion in high-confinementmode discharges in the National Spherical Torus Experiment," Phys. Rev. Lett., vol. 25, p. 135004, 2010.

[7] S. A. Sabbagh, J. W. Berkery, R. E. Bell, J. M. Bialek, S. P. Gerhardt, J. E. Menard, R. Betti, D. A. Gates, B. Hu, O. N. Katsuro-Hopkins, B. P. LeBlanc, F. M. Levinton, J. Manickam, K. Tritz, and H. Yuh, "Advances in global mhd mode stabilization research on NSTX," Nucl. Fus., vol. 50, p. 025020, 2010.

[8] R. Raman, D. Mueller, B. A. Nelson, T. R. Jarboe, S. Gerhardt, H. W. Kugel, B. LeBlanc, R. Maingi, J. Menard, M. Ono, S. Paul, L. Roquemore, S. Sabbagh, V. Soukhanovskii, and NSTX Research Team, "Demonstration of tokamak ohmic flux saving by transient coaxial helicity injection in the National Spherical Torus Experiment," Phys. Rev. Lett., vol. 104, p. 095003, March 2010.

[9] T. K. Gray, R. Maingi, V. A. Soukhanovskii, J. E. Surany, J.-W. Ahn, and A. G. McLean, "Dependence of divertor heat flux widths on heating power, flux expansion, and plasma current in the NSTX," J. Nucl. Mater., 2011, in press.

[10] D. D. Ryutov, "Geometrical properties of a snowflake divertor," Phys. Plasmas, vol. 14, p. 064502, 2007.

[11] P. M. Valanju, M. Kotschenreuther, S. M. Mahajan, and J. Canik, "Super$\mathrm{X}$ divertors and high power density fusion devices," Phys. Plasmas, vol. 16 , p. $056110,2009$.

[12] V. A. Soukhanovskii, J.-W. Ahn, R. E. Bell, D. A. Gates, S. Gerhardt, R. Kaita, E. Kolemen, B. P. LeBlanc, R. Maingi, M. Makowski, R. Maqueda, A. G. McLean, J. E. Menard, D. Mueller, S. F. Paul, R. Raman, A. L. Roquemore, D. D. Ryutov, S. A. Sabbagh, and H. A. Scott, "Taming the plasma material interface with the snowflake divertor in NSTX," Nucl. Fus., vol. 51, p. 012001, 2011. 